\title{
Progressive Familial Intrahepatic Cholestasis with High $\gamma$-Glutamyltranspeptidase Levels in Taiwanese Infants: Role of MDR3 Gene Defect?
}

\author{
HUEY-LING CHEN, PEI-SHIN CHANG, HEY-CHI HSU, JYH-HONG LEE, YEN-HSUAN NI, \\ HONG-YUAN HSU, YUNG-MING JENG, AND MEI-HWEI CHANG \\ Departments of Pediatrics [H.L.C., P.S.C, J.H.L., Y.H.N., H.Y.H., M.H.C.] and Pathology [H.C.H., \\ Y.M.J.], National Taiwan University Hospital, No. 7, Chung-Shan South Road, Taipei 100, Taiwan
}

\begin{abstract}
MDR3 P-glycoprotein mediates canalicular phospholipid transport in hepatocytes. Defects in the MDR3 gene have been found to cause a subtype of progressive familial intrahepatic cholestasis (PFIC) with high $\gamma$-glutamyltranspeptidase (GGT) levels. Affected children develop proliferation of biliary epithelium, portal inflammation, and biliary cirrhosis. The frequency of $M D R 3$ mutations in patients with high GGT-PFIC is unclear. There have been no Asian patients reported to carry $M D R 3$ mutations. To determine the role of MDR3 defects in chronic cholestatic patients, we studied six Taiwanese children from five families who presented high GGT-PFIC among 47 patients with infantile onset chronic intrahepatic cholestasis. Sequence analysis of MDR 3 cDNA from liver tissues was performed. Only one patient had mutation in the MDR3 gene. This patient had a homozygous 719-bp deletion (nucleotide 287 to 1005) of liver
\end{abstract}

ABSTRACT

cDNA encompassing exon 5 to 9 and leading to protein truncation. The onset age was $1 \mathrm{y}$ in contrast with the other five patients who presented neonatal cholestasis. Four patients without mutation, including one sibling pair, exhibited histologic features of prominent portal fibrosis leading to advanced biliary cirrhosis that were indistinguishable from the case of MDR3 mutation. We concluded that mutations in MDR3 accounted for approximately $2 \%(1 / 47)$ of infantile onset chronic cholestasis in Taiwan. Those patients presenting high GGT-PFIC with early onset cholestasis but without $M D R 3$ mutation probably had inheritable disorders remaining to be clarified. (Pediatr Res 50: 50-55, 2001)

\section{Abbreviations}

PFIC, progressive familial intrahepatic cholestasis

GGT, $\gamma$-glutamyltranspeptidase
PFIC is an autosomal recessive disorder that was originally reported in Amish kindred (1). Patients are characterized as having early onset cholestasis, progressive liver cirrhosis, and hepatic failure in the first or second decade (2-5). Most patients have normal or low GGT levels, normal cholesterol levels, and low chenodeoxycholic acid concentration in the bile. The genetic defects have recently been elucidated to occur in familial intrahepatic cholestasis $1(F I C l)$ or bile salt export pump $(B S E P)$ genes $(6,7)$. A third type of PFIC was found in patients with high GGT levels who had defective $M D R 3$ gene (formal genetic name, $A B C B 4$ ) expression $(8,9)$. Affected patients have extremely low levels of biliary phospholipids and developed biliary cirrhosis in early childhood.

MDR3 p-glycoprotein, a member of the superfamily of ATP-binding cassette $(\mathrm{ABC})$ transporters, confers canalicular transport of phospholipid and is a rate-limiting step in phos-

Received September 6, 2000; accepted February 8, 2001.

Correspondence: Mei-Hwei Chang, M.D., 7F, No. 7, Chung-Shan South Road, Department of Pediatrics, National Taiwan University Hospital, Taipei 100, Taiwan; e-mail: mhchang@ha.mc.ntu.edu.tw

Supported by grants from the National Science Council, Taiwan (NSC 89-2314-B-002040), and the National Taiwan University Hospital (88N130). pholipid secretion (10-13). Mdr2 (the mice homologue of human $M D R 3$ gene) knockout mice exhibited progressive liver damage and cirrhosis that highly resemble the pathology of PFIC (14). The pathophysiology resides in lack of phospholipid protection in the bile against the detergent effect of bile salts, resulting in damage to the biliary epithelium, bile ductular proliferation, and progressive portal fibrosis. The corresponding human disease has subsequently been found in pediatric PFIC patients with high GGT levels (8). Evidences showed defective MDR3 expression in their liver and extremely low levels of phospholipid in the bile. Two mutations, a 7-bp deletion and a $957(\mathrm{C} \rightarrow \mathrm{T})$ nonsense mutation, were found in a Turkish and a North African boy of consanguineous parents (9). Heterozygous MDR3 mutations have also been found in association with cholestasis of pregnancy (15).

Reports specifying high GGT-PFIC are limited, partly because of its rarity and the obscure etiology. The frequency of MDR3 mutations among the patients with chronic intrahepatic cholestasis is unclear. There have been no Asian children reported with $M D R 3$ mutations. In the present study, we report six Taiwanese children presenting with high GGT-PFIC among 47 patients of infantile onset chronic intrahepatic cholestasis. 
To disclose the underlying molecular basis, we performed sequence analysis of $M D R 3$ cDNA from six liver tissues and found one patient to have novel MDR3 mutation.

\section{METHODS}

Subjects. From 1980 to 1998, a total of 47 patients had been admitted to the Department of Pediatrics in National Taiwan University Hospital for infantile onset chronic intrahepatic cholestasis. All the patients had onset of intrahepatic cholestatic liver disease before 12 mo of age, and the disease lasted for more than 6 mo. A thorough search for known cholestasis in infancy had been done. Examinations included observations of stool color, abdominal sonography, liver histology, and hepatobiliary scan. Patients who had extrahepatic cholestasis were excluded as previously defined (16). Patients with viral hepatitis $\mathrm{B}$ and $\mathrm{C}$, congenital infections, organic acidemia, total parenteral nutrition, drug-related cholestasis, or cholestasis secondary to sepsis or ischemic injury were excluded. Alagille syndrome was diagnosed based on the presence of major clinical criteria in addition to liver histopathology (17). Serum $\alpha-1$-antitrypsin and bile acid level were checked on every patient.

Among the 47 patients, Alagille syndrome was diagnosed in 18 , inborn errors of bile acid synthesis in four, neonatal Dubin-Johnson disease in two, and tyrosinemia in one. No identifiable etiology was found in the remaining 21 patients, including six patients with high serum GGT levels (above 94 $\mathrm{U} / \mathrm{L}$ according to the normal range of infants in our hospital) and 15 with normal serum GGT levels.

To investigate the etiology of the six patients with high GGT levels, either endoscopic retrograde cholangiography, magnetic resonance cholangiopancreatography, or operative cholangiography was performed and revealed no structural anomalies of biliary trees. Needle biopsy of the liver was performed in all patients with informed consent from the parents. These patients were followed for 17 mo to $16 \mathrm{y}$. The present study was approved by the Institutional Review Board.
Duodenal juice analyses. Duodenal fluid was obtained from case 2 by endoscopic duodenal intubation. Bile acid level was measured by an enzymatic assay using the modified $3 \alpha$ hydroxysteroid dehydrogenase method (Enzabile-2, Daiichi, Japan). Phospholipid concentration was measured by a chemical method using the MPR2 kit (Boehringer Mannheim, Mannheim, Germany).

Genetic study. Total cellular RNA was extracted from frozen liver samples by single-step acid guanidinium thiocyanatephenol-chloroform method or RNeasy minikit (Qiagen, Germany). The isolated RNA was reverse transcribed using random hexamer (Promega Corp., Madison, WI, U.S.A.) and reverse transcriptase (Superscript, GIBCO BRL, Eggenstein, Germany) at $42^{\circ} \mathrm{C}$ for $45 \mathrm{~min}$ and inactivated at $72^{\circ} \mathrm{C}$ for 15 min. The cDNA was subjected to PCR using 13 sets of primers deduced from the entire coding sequences of the MDR3 gene. Primer sequences are listed in Table 1 . The amplified fragments range from 300 to $650 \mathrm{bp}$. The purified PCR products were subjected to direct DNA sequencing. Sequence analysis was performed by the dideoxynucleotide chain-termination method using the ABI 373A or 377 DNA Automated Sequencer (Applied Biosystems, Foster City, CA, U.S.A.). Each test was duplicated.

To confirm the cDNA deletion found in case 5, two sets of PCR primers were designed to analyze the corresponding genomic DNA. DNA from liver tissue was extracted using the QIAamp DNA minikit (Qiagen, Germany). Primer set A amplified a 241-bp segment flanking the exon 4 and intron 4 junction. Primer B amplified a 212-bp segment flanking the intron 4 and exon 5 junction. DNA from two normal subjects and two patients with biliary atresia were used as control.

\section{RESULTS}

Clinical and histologic characterization. The clinical, biochemical, and histologic data of the six patients are shown in Table 2. Neonatal onset of cholestasis was found in five patients except case 5 who presented pruritus at 1 y of age. The

Table 1. PCR primers

\begin{tabular}{|c|c|c|c|}
\hline $\begin{array}{c}\text { Primer } \\
\text { No. }\end{array}$ & Sense $5^{\prime}$ to $3^{\prime}$ (position*) & Antisense $5^{\prime}$ to $3^{\prime}$ (position*) & $\begin{array}{c}\text { Tm } \\
\left({ }^{\circ} \mathrm{C}\right) \\
\end{array}$ \\
\hline 1 & CCT-GCC-AGA-CAC-GCG-CGA-GGT-TC (-32 -9) & TCA-TCT-GTT-AGC-CGC-GTA-TTG-AGT-TC (514-539) & 64 \\
\hline 2 & TGC-TGG-AGT-TCT-TGT-TGC-TG (372 391) & AAC-GGC-TGC-AGA-GAG-TCC-TA $(680 \sim 699)$ & 62 \\
\hline 4 & GCC-CCA-TGT-ATT-GAT-GCT-TT (1051 1070) & GCC-CTC-ATC-AGG-GTC-ATA-GA (1334 1353) & 60 \\
\hline 5 & TCC-AGC-TGA-TAC-AGA-GGC-TCT $(1316 \sim 1336)$ & CAG-CTT-CAC-TTT-CTG-TGT-CCA (1687 1708) & 62 \\
\hline 6 & TCT-GCT-GGA-TGA-GGC-CAC-GTC (1662 1682) & CTT-CAA-GTC-CAT-CGG-TTT-CCA-CAT-C (2045 2068) & 62 \\
\hline 9 & ATT-GCT-GTG-TCA-GGA-ATT-GTT (2599 2619) & AAG-CGC-ATA-TGT-CCA-TTC-A (2891 2909) & 62 \\
\hline 10 & GGC-ACA-CAT-CTA-TGG-AAT-TAC (2789 2809) & TTC-ACT-GTA-GCT-GTC-AAT-CAG (3046 3066) & 62 \\
\hline 11 & GAT-TGA-CAG-CTA-CAG-TGA-AGA (3048 3068) & ATG-AAA-GGA-TGT-ATG-TTG-GCA (3450 3470) & 60 \\
\hline 12 & AGG-TGA-AGA-AAG-GCC-AGA-CA (3173 3192) & GCT-GAG-TCC-CCT-TAT-CTC-CC (3504 3523) & 62 \\
\hline 13 & CGA-GAC-GTT-ACC-CCA-CAA-AT (3471 3490) & CCT-GGA-CAC-TGA-CCA-TTG-AA (3801 3820) & 60 \\
\hline A & CAA-CTC-CCA-AAT-TTT-TAC-CCA (exon 4) & ACT-CCG-ATT-GGC-AGG-ATA-AAT (intron 4) & 60 \\
\hline
\end{tabular}

PCR primers for amplification of MDR3 cDNA (1-13) and partial genomic DNA (A and B).

* Nucleotide position 1 is the A in the ATG translation initiation codon in the MDR3 cDNA sequence.

Tm: annealing temperature. 


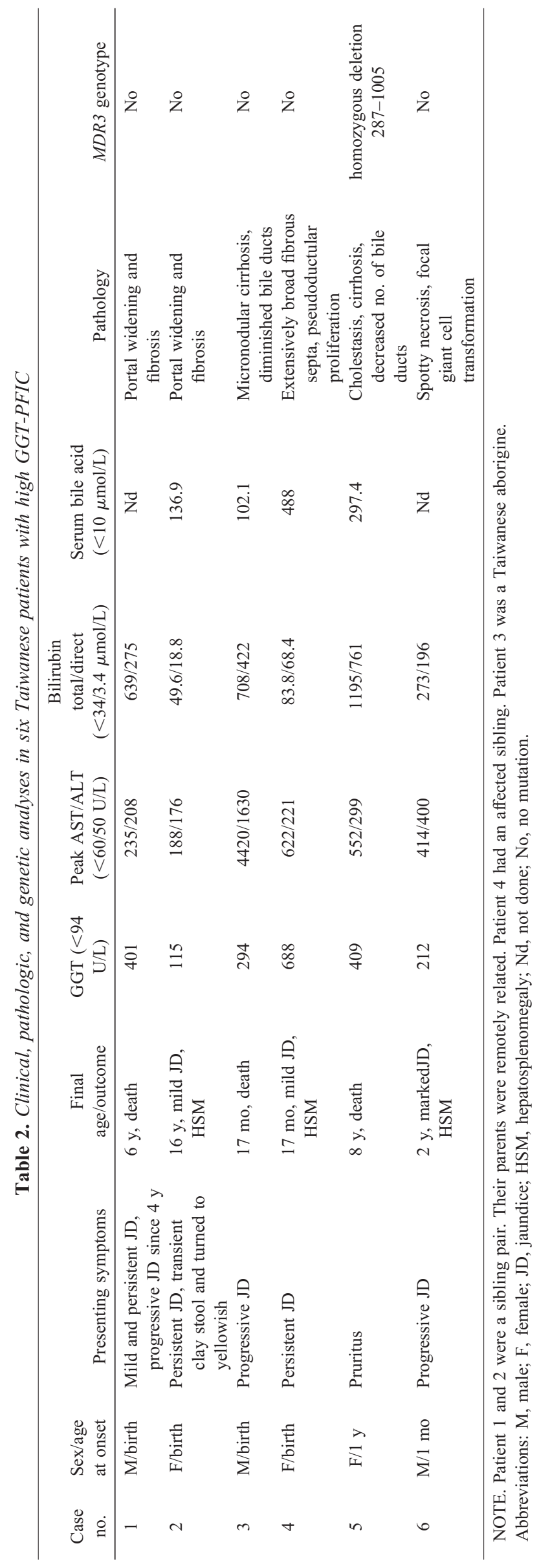

GGT levels ranged from 1.2 to 9.8 times normal value. Transaminase and bilirubin levels were elevated. Pruritus was common. There was no specific extrahepatic manifestation. Hepatobiliary scan was performed in four patients, and two showed no radioactivity in the duodenum. Further studies in endoscopic retrograde cholangiography and laparotomy revealed patency of biliary trees. Cases 1 to 5 shared common clinical and histopathologic features. Portal hypertension developed in infancy or early childhood with splenomegaly and/or varices in all. Coagulopathy and esophageal variceal bleeding were noted in the advanced disease stage. Liver histology showed significant widening and fibrosis of the portal areas with progression to liver cirrhosis (Fig. 1). No identifiable copper or iron depositions were noted in the liver biopsy samples. Duodenal juice analysis of case 2 revealed phospholipid and bile salt concentration to be normal range (19 and $40 \%$ of total biliary lipids). Cases 1 and 2 were a sibling pair; their parents were remotely related. Case 4 had an affected sibling with identical phenotype.

In the remaining patient (case 6), liver histology showed frequent spotty necrosis and occasional giant cell transformation. There were no significant changes in portal areas and bile ducts in this patient.

Prognosis. Three of the six patients eventually died of hepatic failure or complications of liver cirrhosis at the age of 17 mo to $8 \mathrm{y}$.

Case report. Cases 1 and 2. A 17-y-old girl was noted to have jaundice since birth. The stool was initially clay colored but turned to yellowish after 3 wk of age. Progressive hepatosplenomegaly developed, but jaundice gradually ameliorated. She grew up well without physical disturbances. Abdominal sonography revealed marked splenomegaly with prominent collateral vessels at splenic hilum. Bilirubin levels remained mildly elevated at approximately $34 \mu \mathrm{mol} / \mathrm{L}$. Endoscopic retrograde cholangiography revealed normal intrahepatic and extrahepatic biliary structure. There is no esophageal varix. Her younger brother had mild jaundice since birth, and it persisted for years. He developed progressive jaundice and esophageal varices at the age of 5 . He died of variceal bleeding and hepatic failure at the age of 6 .

Case 5. This 6-y-old girl had pruritic skin since the age of 1 y. Jaundice gradually appeared and became apparent by the age of 5 . At this time, she was first brought to a medical doctor, and hepatosplenomegaly was marked. She is the first child with two unaffected younger sisters. The parents were nonconsanguineous. The liver biopsy showed extensive portal fibrosis and cirrhosis with decreased numbers of interlobular bile ducts. Jaundice and portal hypertension gradually progressed. She died of hepatic failure at the age of $8 \mathrm{y}$.

Analyses for MDR3 gene. MDR3 gene was analyzed in all six patients. Only one (case 5) had MDR3 mutation. A homozygous 719-bp deletion (nucleotide 287 to 1005 of coding sequence) of liver cDNA was found that encompassed exon 5 to 9 and led to a frameshift (Fig. 2). The predicted consequence is the substitution of 19 novel amino acids after residue 96, followed by protein truncation. To further determine whether a splicing error or deletion occurred in genomic DNA, two sets of primers encompassing the start site and end site of intron 4 

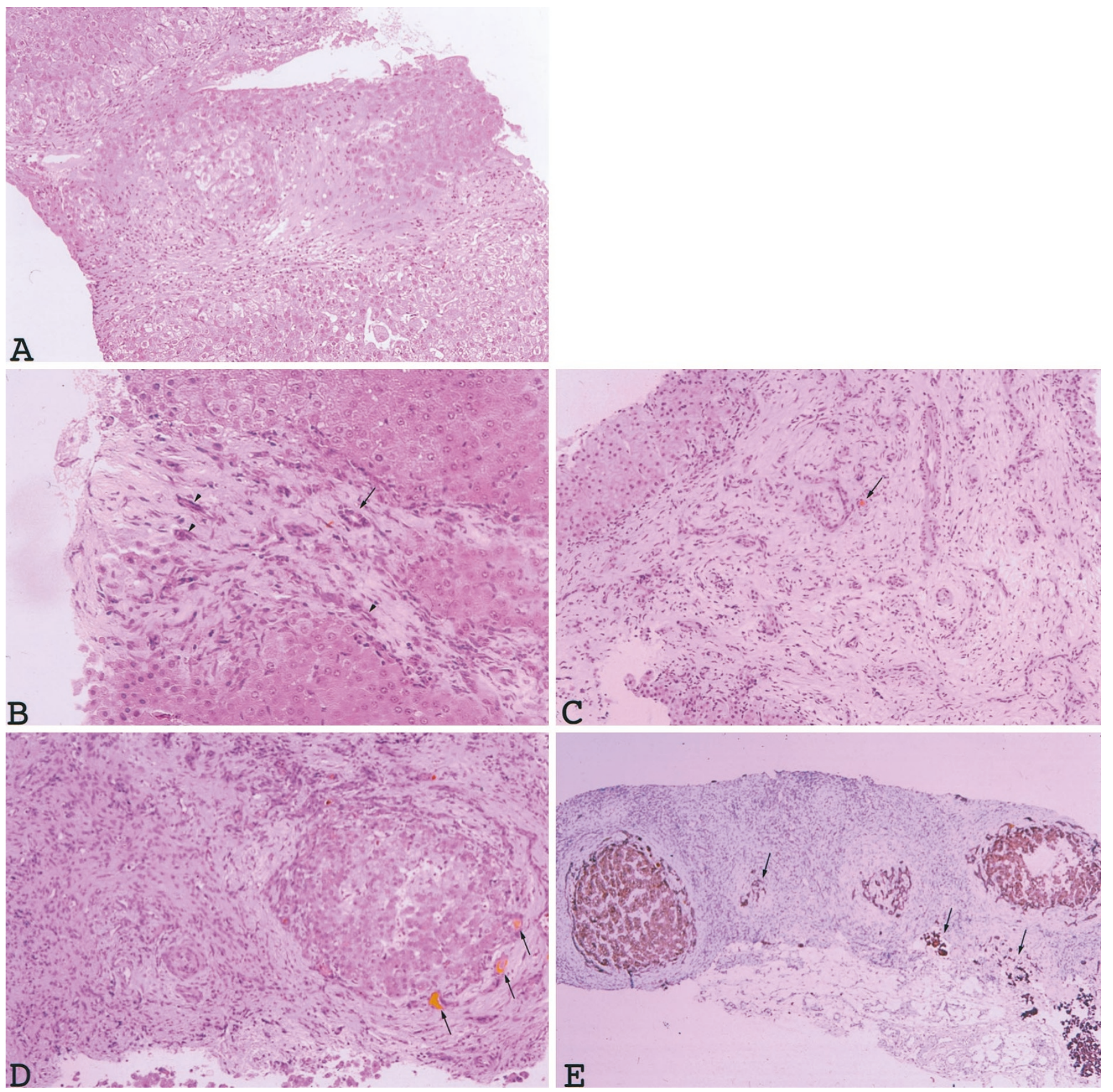

Figure 1. Liver histology from patients with high GGT-PFIC. $(A)$ Case 5, with deletion in MDR3 gene. Needle biopsy taken at 6 y of age shows liver cirrhosis. Occasional canalicular cholestasis (not shown) is also present. $(B)-(E)$ Patients without $M D R 3$ gene mutation. (B) Case 2 . Needle biopsy at 7 y shows prominent portal area with fibrosis. Small interlobular bile duct (arrow) and proliferative pseudoductules (arrowheads) are also shown. The liver lobular architecture is preserved. (C) Case 4. Needle biopsy of an 8-mo-old girl with portal hypertension shows biliary cirrhosis with extremely broad fibrous septa, prominent pseudoductular proliferation, and occasional bile plugs (arrow) but no discernible interlobular bile duct. $(D)$ and $(E)$ Case 3. Needle biopsy at 17 mo of age shows postnecrotic-type cirrhosis with micronodules widely separated by broad and dense fibrotic septa. The vessels are prominent, but interlobular bile ducts are absent $(D)$. Immunohistochemical stain for cytokeratin confirms cirrhotic nodules and remnants of hepatocytes with ductular transformation (arrows) in the fibrotic areas but no interlobular bile ducts $(E)$. $(A)-(D)$ Hematoxylin-eosin; $(A),(C)$, and $(D) \times 135 ;(B) \times 270 ;(E)$ immunohistochemical stain for cytokeratin, $\times 52$.

were used. Normal PCR products were found using primer set A at the start site of intron 4, but no amplification products were detected when primer set B located at intron 4 and exon 5 junction was used (Fig. 3). Thus, a deletion in genomic DNA was predicted in this region between intron 4 and intron 9, which included an approximately $17-\mathrm{kb}$ genome length. A 504 $\mathrm{C} \rightarrow \mathrm{T}$ homozygous single nucleotide polymorphism, which resulted in no amino acid change, was found in all the other five patients.

\section{DISCUSSION}

In the present study, we found that $M D R 3$ mutations accounted for approximately $2 \%(1 / 47)$ of patients with infantile 

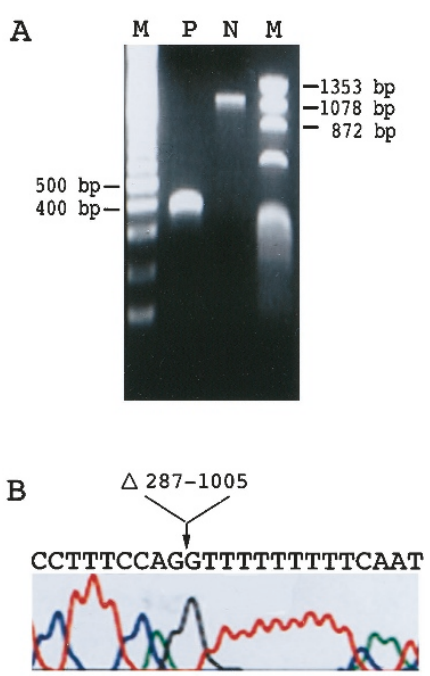

Figure 2. Mutation in $M D R 3$ gene (case 5). (A) PCR of cDNA from liver tissue revealed a normal amplified segment of $1122 \mathrm{bp}$ from control liver and a 403-bp segment from patient liver. $M$ indicates markers; $P$, patient; $N$, control liver. $(B)$ Sequence analysis of segment $\mathrm{P}$ discloses a deletion from nucleotide 287 to 1005 in coding sequence.

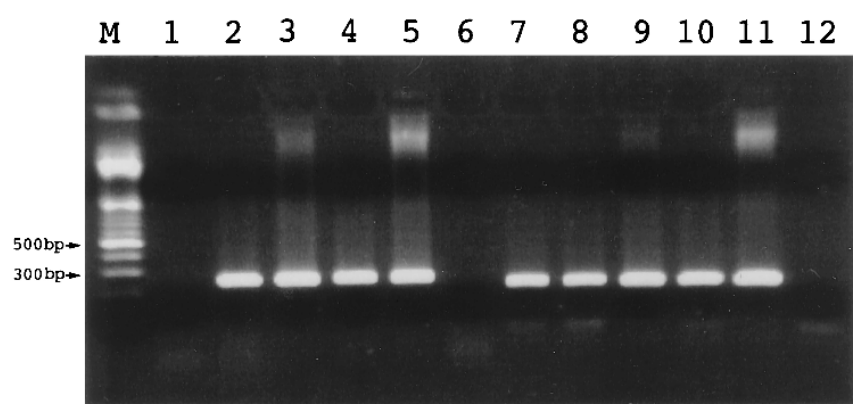

Figure 3. Deletion of genomic DNA in case 5 (line 1). Primer set B amplified a 212-bp segment flanking the intron 4 and exon 5 junction (lane 1 to 6 ). Primer set A amplified a 241-bp segment flanking the exon 4 and intron 4 junction (lane 7 to 12 ). Lane 1 and 7, case 5; lane 2, 3, 8, 9, normal control; lane $4,5,10,11$, patients with biliary atresia; lane 6 and 12 , negative control.

onset chronic intrahepatic cholestasis in Taiwan. The only case with a novel mutation in MDR3 manifested pruritus at $1 \mathrm{y}$ instead of neonatal jaundice. This implies that an MDR3 defect is not a common cause of high GGT intrahepatic cholestasis in infancy, especially in neonatal cholestasis. The late presentation in our patient was not due to a minor genetic alteration, because the deletion in this patient resulted in premature protein truncation with predicted loss of protein function. In our case, the liver histology showed extensive portal fibrosis and cirrhosis with paucity of interlobular ducts, whereas the reported cases of MDR3 defects showed bile ductular proliferation $(8,9)$. This may be due to the advanced disease stage or due to sampling variations in needle biopsy. In patients with low GGT-PFIC, both bile duct proliferation and bile duct paucity have been reported (2).

It is noteworthy that Alagille syndrome is the most prevalent cause of chronic intrahepatic cholestasis. Because Alagille syndrome also presents with high GGT levels, a careful clinical search for features of Alagille syndrome should be done for all cases of high GGT intrahepatic cholestasis.
Studies on high GGT-PFIC patients are limited. This subtype was first identified by its similarity to the phenotype of $m d r 2$ knockout mice $(8,14)$. To date, four patients have been reported to have a defective $M D R 3$ gene $(8,9)$. The disease onset age was beyond $1 \mathrm{y}$ in three of the four patients. The first symptoms were most commonly hepatosplenomegaly and pruritus without jaundice. This corresponds to the proposed pathophysiology of an MDR3 defect in that deficiency of biliary phospholipid leads to bile epithelium damage by bile salts, resulting in the proliferation of biliary epithelium, portal fibrosis, and cirrhosis $(13,14)$. Therefore, symptoms of portal hypertension often precede symptoms of cholestasis and hepatocellular injury. In contrast, patients with PFIC-1 and 2 often present jaundice and elevated transaminase levels as neonates or in early infancy. We speculated that patients with MDR3 deficiency (or PFIC-3) differ from PFIC-1, 2 largely by its presentation symptoms and onset age. In the present study, we recruited children with cholestasis onset before $1 \mathrm{y}$ of age. This may be the reason the frequency of MDR3 mutation is low. Larger series of cases with MDR3 deficiency would clarify the disease spectrum and may disclose a wider range of onset age in the affected individuals.

In four patients without $M D R 3$ mutation, the liver histology was indistinguishable from the reported cases and our single patient who had MDR3 mutation. These patients who expressed PFIC-3-like phenotype but without MDR3 mutation may represent a new form of PFIC characterized by high serum GGT, early onset cholestasis, and extensive portal fibrosis. Evidence of a normal level of biliary phospholipid in our patients excluded defects in phospholipid excretion. Another disease entity with neonatal cholestasis with high GGT levels has been reported as neonatal sclerosing cholangitis $(18,19)$. Affected children had characteristic cholangiographic and liver histologic pictures that were different from our patients. Many other forms of progressive cholestasis have been reported with well-defined ethnic or geographic predominance, such as North American Indian childhood cirrhosis (NAIC), Norwegian cholestasis, Greenland Eskimo cholestasis, nonsyndromic paucity of bile ducts, and Cree-Ojibwa cholestasis (20). Linkage analysis is now underway to elucidate the molecular basis and pathogenesis in the above-mentioned patients. Further discoveries of new genes causing cholestasis or known genes with newly identified phenotype are expected. These patients will be more appropriately classified by specific gene defects in the future.

For the remaining one patient with a distinct histopathologic feature, an insult leading to hepatocellular damage is suspected. Possibilities include toxins, hepatic enzymatic defects, or inborn errors of bile acid synthesis. Although primary inborn errors of bile acid synthesis usually manifest low serum GGT and low serum bile acid levels, the diagnosis cannot be completely ruled out before a detailed examination using gas chromatography mass spectrometry is performed.

In conclusion, we reported the first case of Asian children with a novel MDR3 gene defect. Clinical suspicions of MDR3 deficiency should be directed to those who present with hepatosplenomegaly, pruritus, with or without jaundice. cDNA sequencing is helpful to confirm the genetic diagnosis. We 
suggest that high GGT-PFIC is a heterogeneous disease. Some patients with neonatal intrahepatic cholestasis with high GGT levels still remained idiopathic. Further investigations of the genetic basis causing high GGT-PFIC should continue.

Acknowledgments. The authors thank Dr. Shao-Chun Lu for measurement of phospholipids, Dr. Jason C. Lin for referring the patients, Dr. Daw-Jen Tsuei for technical advice, and Li-Ying Wang for excellent technical assistance.

\section{REFERENCES}

1. Clayton RJ, Iber FL, Ruebner BH, McKusick VA 1969 Byler disease. Fatal familial intrahepatic cholestasis in an Amish kindred. Am J Dis Child 117:112-124

2. Alonso EM, Snover DC, Montag A, Freese DK, Whitington PF 1994 Histologic pathology of the liver in progressive familial intrahepatic cholestasis. J Pediatr Gastroentol Nutr 18:128-133

3. Whitington PF, Freese DK, Alonso EM, Schwarzenberg SJ, Sharp HL 1994 Clinical and biochemical findings in progressive familial intrahepatic cholestasis. J Pediatr Gastroenterol Nutr 18:134-141

4. Muller M, Jansen PLM 1997 Molecular aspects of hepatobiliary transport. Am J Physiol 272:539-1542

5. Bull LN, Carlton VE, Stricker NL, Baharloo S, DeYoung JA, Freimer NB, Magid MS, Kahn E, Markowitz J, DiCarlo FJ, McLoughlin L, Boyle JT, Dahms BB, Faught PR, Fitzgerald JF, Piccoli DA, Witzleben CL, O'Connell NC, Setchell KDR, Agostini RM, Kocoshis SA, Reyes J, Knisely AS 1997 Genetic and morphological findings in progressive familial intrahepatic cholestasis (Byler disease [PFIC-1] and Byler syndrome): evidence for heterogeneity. Hepatology 26:155-164

6. Strautnieks SS, Bull LN, Knisely AS, Kocoshis SA, Dahl N, Arnell H, Sokal E, Dahan K, Childs S, Ling V, Tanner S, Kagalwalla AF, Nemeth A, Pawlowska J, Baker A, Mieli-Vergani G, Freimer NB, Gardiner RM, Thompson RJ 1998 A gene encoding a liver-specific $\mathrm{ABC}$ transporter is mutated in progressive familial intrahepatic cholestasis. Nat Genet 20:233-238

7. Bull LN, van Eijk MJT, Pawlikowska L, DeYoung JA, Juijn JA, Liao M, Klomp LWJ, Lomri N, Berger R, Scharschmidt BF, Knisely AS, Houwen RHJ, Freimer NB 1998 A gene encoding a P-type ATPase mutated in two forms of hereditary cholestasis. Nat Genet 18:219-224
8. Deleuze JF, Jacquemin E, Dubuisson C, Cresteil D, Dumont M, Erlinger S, Bernard O, Hadchouel M 1996 Defect of multidrug-resistance 3 gene expression in a subtype of progressive familial intrahepatic cholestasis. Hepatology 23:904-908

9. De Vree JM, Jacquemin E, Sturm E, Cresteil D, Bosma PJ, Aten J, Deleuze JF, Desrochers M, Burdelski M, Bernard O, Oude Elferink RPJ, Hadchouel M 1998 Mutations in the $M D R 3$ gene cause progressive familial intrahepatic cholestasis. Proc Natl Acad Sci USA 95:282-287

10. Schinkel AH, Roelofs MEM, Borst P 1991 Characterization of the human MDR3 P-glycoprotein and its recognition by P-glycoprotein-specific monoclonal antibodies. Cancer Res 51:2628-2635

11. Lincke CR, Smit JJM, Van der Velde-Koerts T, Borst P 1991 Structure of the human MDR3 gene and physical mapping of the human MDR locus. J Biol Chem 266:53035310

12. Bliek AM, Kooiman PM, Schneider C, Borst P 1988 Sequence of mdr3 cDNA encoding a human P-glycoprotein. Gene 71:401-411

13. Oude Elferink RPJ, Ottenhoff R, Wijland M, Smit JJM, Schinkel AH, Groen AK 1995 Regulation of biliary lipid secretion by mdr2 P-glycoprotein in the mouse. J Clin Invest 95:31-38

14. Smit JJM, Schinkel AH, Oude Elferink RPJ, Groen AK, Wagenaar E, van Deemter L, Mol CAAM, Ottenhoff R, van der Lugh NM, van Roon MA, van der Valk MA, Offerhaus GJA, Berns AJM, Bosrt P 1993 Homozygous disruption of the murine mdr2 P-glycoprotein gene leads to a complete absence of phospholipid from bile and to liver disease. Cell 75:451-462

15. Jacquemin E, Cresteil D, Manouvrier S, Boute O, Hadchouel M 1999 Heterozygous non-sense mutation of the MDR3 gene in familial intrahepatic cholestasis of pregnancy. Lancet 353:210-211

16. Lai MW, Chang MH, Hsu SC, Hou JW, Hsu HC, Su CT, Kao CL, Lee CY 1994 Differential diagnosis of cholestasis in infancy: a prospective study. J Pediatr Gastroenterol Nutr 18:121-127

17. Alagille D, Estrada A, Hadchouel M, Gautier M, Odierre M, Dommergues JP 1987 Syndromic paucity of interlobular bile ducts (Alagille syndrome or arteriohepatic dysplasia): review of 80 cases. J Pediatr 110:195-200

18. Amedee-Manesme O, Bernard O, Brunelle F, Hadchouel M, Polonovski C, Baudon JJ, Beguet P, Alagille D 1987 Sclerosing cholangitis with neonatal onset. J Pediatr 111:225-229

19. Baker AJ, Portmann B, Westably D, Wilkinson M, Karani J, Mowat AP 1993 Neonatal sclerosing cholangitis in two siblings: a category of progressive intrahepatic cholestasis. J Pediatr Gastroenterol Nutr 17:317-322

20. Drouin E, Mitchell GA, Rasquin-Weber A 2000 Other inherited cholestatic disorders In: Walker WA, Durie PR, Hamilton JR, Walker-Smith JA, Watkins JB (eds) Pediatric Gastrointestinal Disease, 3rd Ed. BC Decker Inc, Hamilton, Ontario, pp $1211-1218$ 